Discussion Paper No. 896

\title{
OLDER SISTERS AND YOUNGER BROTHERS: \\ THE IMPACT OF SIBLINGS ON PREFERENCE FOR COMPETITION
}

\author{
Hiroko Okudaira \\ Yusuke Kinari \\ Noriko Mizutani \\ Fumio Ohtake \\ Akira Kawaguchi
}

March 2014

The Institute of Social and Economic Research Osaka University

6-1 Mihogaoka, Ibaraki, Osaka 567-0047, Japan 


\title{
Older Sisters and Younger Brothers:
}

\section{The Impact of Siblings on Preference for Competition ${ }^{*}$}

\author{
Hiroko Okudaira $^{\dagger}$ \\ Okayama University
}

Yusuke Kinari $^{\ddagger}$

Kyushu University

Noriko Mizutani ${ }^{\S}$

Institute for Research on Household Economics

\author{
Fumio Ohtake** \\ Osaka University
}

\author{
Akira Kawaguchi $^{\dagger \dagger}$ \\ Doshisha University
}

This version: March 2014

\footnotetext{
* We are grateful to Yukiko Abe, Peter Kuhn, Edward Lazear, Hodaka Morita, Hideo Owan, Masaru Sasaki, Kathryn Shaw, and seminar participants at the 2012 Trans-Pacific Labor Seminar in Hawaii for their helpful comments. All remaining errors are our own. We also thank Kiyoko Murahima and Shizuka Yamagiwa for their assistance. Authors acknowledge a research grant from the Japan Society for the Promotion of Science.

Okudaira acknowledges a research grant from Okayama University.

† Department of Economics, Okayama University, 1-1-3, Tsushima-naka, Kita-ku, Okayama city, Okayama 700-8530, Japan; okudaira@e.okayama-u.ac.jp

‡ Graduate School of Economics, Kyushu University; kinari@en.kyushu-u.ac.jp

§ Institute for Research on Household Economics; mizutani@kakeiken.or.jp

** Institute of Social and Economic Research, Osaka University; ohtake@iser.osaka-u.ac.jp

${ }^{\dagger \dagger}$ Graduate School of Policy and Management, Doshisha University; akawaguc@mail.doshisha.ac.jp
} 


\title{
Older Sisters and Younger Brothers:
}

\section{The Impact of Siblings on Preference for Competition}

\author{
This version: March 2014
}

\begin{abstract}
Studies in psychology have long argued the possibility that sibling structure, such as birth order and the gender of siblings, shapes one's feminine and masculine personality traits, such as a preference for competition. In light of recent developments in the economics literature on the gender gap, this implies that familial environment could explain why some women do opt for competition, while the vast majority of women do not and, thus, are underrepresented on the career ladder. By conducting a controlled experiment on Japanese high school students, this study quantifies the impact of sibling structure on one's preference for competition, and examines whether a long-debated sibling hypothesis in psychology is supported from the viewpoint of experimental economics. Consistent with the hypothesis, our results reveal that men with older sisters were significantly less likely to enter a competitive environment compared with only sons. This effect is comparable in size to the effect of being female on the decision to compete. Our study also found moderate evidence that women with younger brothers were more likely to compete than only daughters.
\end{abstract}

Journal of Economic Literature Classification Numbers: C91, D03, J16

Keywords: Sibling competition, Gender gap, Preference for competition, Experiment 


\section{Introduction}

Despite numerous attempts to do away with the professional gender gap over the past decades, the so-called "glass-ceiling” on the corporate ladder is still firmly in place in many countries. According to LABORASTA and Eurostat Database, in 2010, the proportion of women in the workplace was similar across countries, ranging from $41.6 \%$ in Korea to $47.5 \%$ in France. On the other hand, the proportion of women in managerial positions in the same year was substantially lower and varied significantly across countries, ranging from $10.1 \%$ in Korea to $30-39 \%$ in European nations. Recent developments in the labor economics literature have made a significant contribution in unfolding the reason behind this gender gap in promotions, showing that otherwise qualified women shy away from competitive environments simply because they dislike competition (Niederle and Vesturlund, 2007). A novel component of the Niederle and Vesturlund study (2007) was its method of extracting individuals' true preference for competition by using a controlled experiment, where subjects were incentivized with pecuniary rewards. In particular, Niedlerle and Vesturlund (2007) asked students at the University of Pittsburgh to engage in math-solving tasks under several payment schemes, including a competitive tournament scheme, and showed that women were significantly less likely to enter into such a competitive environment. Given their results, an important means for increasing female representation in the corporate arena is to find ways to induce these "shy" women to voluntarily opt for competition.

To this end, subsequent studies have focused on whether women's negative attitudes toward competition are driven by nature or by nurture, as this could then dictate potential changes in policy. For example, if the gender difference in preference for competition is innate and thus constituted from biological factors, institutional 
interventions to increase female representation, such as affirmative action, would be justified because such traits are not controlled by institutions. ${ }^{7}$ Conversely, if environmental or social factors contribute to such a preference it would lend support for educational reforms to prompt social learning in women.

In an influential study suggesting for environmental factors in this preference for competition, Gneezy et al. (2009) conducted a simple experiment in a patriarchal tribe, the Maasai, and a matrilineal tribe, the Khasi. They found that Maasai men opted for competition significantly more often than Maasai women did, while Khasi women chose competition more often than Khasi men did. This gender difference between the tribes suggests the importance of socially defined gender roles in shaping attitudes toward competition. Similarly, a series of studies by Alison Booth and her co-authors revealed that single-sex schools or classrooms nurture more competitive attitudes and encourage risk-taking behavior in women (Booth et al., 2014; Booth and Nolen, 2012a, 2012b; Booth et al., 2011). ${ }^{8}$ There is also evidence that suggests that having same-sex instructors in introductory math or science courses encourages women to major in math or engineering (Carrell et al., 2010), indicating that having a same-sex role model is an environmental factor that could induce women to make choices that they otherwise would not.

This paper designed a laboratory experiment to determine whether the gender gap in preference for competition arises from another environmental factor, namely familial

\footnotetext{
7 'By-nature' studies reported that gender differences in competitive attitudes are influenced by the fluctuation of sex hormones (Buser, 2012; Wozniak et al., 2014; Guéguen, 2012; Dreber and Hoffman, 2007; Archer, 2006; Hoffman and Gneezy, 2010). Prenatal exposure to male sex hormones is also known to predict long-term profitability in financial traders in the City of London (Coates et al., 2009) and performance in sports, such as rankings for sumo-wrestlers (Tamiya et al., 2012).

${ }^{8}$ Fryer and Levitt (2012) obtained evidence suggesting that gender inequality translates into poor female math performance only after excluding participants from Islamic countries where classrooms are segregated by gender.
} 
environment, to which little attention has been paid in the economics literature. In particular, we examined whether sibling structure, such as birth-order or the gender of other siblings, shapes one’s propensity to compete.

Sibling structure may be an especially important environmental contributor to personality because, according to some psychologists, through interactions with their siblings, some women may grow to willingly take part in competition. Based on an observational study by Koch (1954) on primary school students and their siblings, Brim (1958) reported a tendency for mixed-gender sibling pairs to assimilate traits more typically associated with the opposite-sex. For instance, older girls with younger brothers are reported to have more masculine traits than their counterparts who have younger sisters, with masculine traits defined as characteristics like "competitiveness" or “self-confidence.” Similarly, boys with older sisters are considered to be substantially more feminine than their counterparts with older brothers, feminine traits constituting more expressive characteristics such as "kindness" or "friendliness." 9 Interestingly, this effect was stronger in older sister and younger brother pairs compared with older brother and younger sister pairs. While the interaction among cross-gender sibling pairs alone could not explain this particular trend, similar phenomena specific to the relationship of older sisters and younger brothers have been raised in other psychological studies (ex. Stewart, 1982).

Sulloway (1996) provides a possible explanation for this trend by suggesting that the effects unique to an older sister / younger brother relationship arise as a result of a mixture of birth order and role-taking. Sulloway's (1996) rationale for the effect of birth order on personality traits is based on the idea of sibling competition in

\footnotetext{
9 Feminine or masculine traits were identified from teachers' ratings of their students, based on a personality classification used in several empirical studies (Brim, 1958).
} 
evolutionary science. Based on Darwin's principle of divergence, Sulloway (1996) argues that siblings differ in their strategies for attracting parental investment depending on their birth order, which eventually comes to shape their personality traits. Specifically, first-born children tend to be more dominant, aggressive, and ambitious, as well as more conservative than later-born children. This is in order to meet their parents' expectations and standards, thereby defending their stakes against younger rivals in regards to their parents' allocation of resources (Sulloway, 1996). ${ }^{10}$ Thus, first-born children, regardless if they are male or female, act as the "alpha-male” in their sibling system (Sulloway, 1996). This could then explain why Brim (1958) observed the stronger "role-taking effect” in older sister / younger brother pairs than for older brother / younger sister pairs.

However, not all psychologists agree with the view that sibling dynamics, especially birth order, have systematic influences on personality traits. In fact, this is one of the longest debated issues in psychology. While birth order effects on personality were first observed as early by Adler (1928), and have since been tested in thousands of studies, a review of the literature by Ernst and Angst (1983) concluded that there were only negligible birth order effects across personality variables. However, subsequent studies, including Sulloway (1996), have attacked the critique by Ernst and Angst (1983). One of the core issues at play is who rated the participants' personality traits in each of the studies. Some investigations reported observations consistent with Sulloway (1996) when personality traits were rated by family members, but not when they were rated by peers or by the subject him or herself (Jefferson et al., 1998; Paulhus et al., 1999; Saroglou and Fiasse, 2003). However, other studies compared several ratings (self,

\footnotetext{
10 Studies have empirically confirmed this birth order theory by directly comparing personality traits (Sulloway and Zweigenhaft, 2010; Healey and Ellis, 2007).
} 
peer, and parent) of personality traits and found no difference between these ratings (Marini and Kurtz, 2011).

This paper goes beyond these past psychological studies by obtaining information regarding one of the key personality traits, preference for competition, using a controlled experiment similar to that used by Niederele and Vesturlund (2007), rather than through subjective ratings. In our experiment, Japanese high school students were asked to solve as many mazes as possible in several tasks with different payment schemes. In order to examine whether individuals opt for a competitive environment, the experimenter asked subjects to select whether they wanted to be compensated under a piece-rate or tournament before they started solving mazes. Since the reward under the tournament scheme depended on the performance of the other members in a randomly assigned group, entry into a tournament represents a voluntary choice for a competitive environment. We then examined what factors, including sibling structure, accounted for tournament choice, and tested whether a long-debated sibling hypothesis in psychology is supported from the viewpoint of experimental economics.

Our study supports the implications stated in Sulloway (1996): males who have older sisters are significantly less likely to choose a tournament scheme than males who have no siblings, while females with younger brothers were more likely to choose tournaments than only daughters were. The magnitude of the effect of sibling structure on competition preference are quite large, with the older sister effect alone cancelling out the typical aversion to tournament entry generally observed among females. 


\section{Methods}

\section{2-1. Participants}

One hundred and thirty-five students from four high schools in the Kyoto area of Japan participated in the study. Participants attended one of four sessions that took place on July 16 and 22 and October 1, 2011. Five confederates took part in the experiment to make up for last-minute participant cancellations, as the experiment had to be conducted in groups of four. Data from the confederates were eliminated from the analysis, although the exclusion of data from subjects who happened to be in the same group as the confederates did not significantly affect the results. Each subject was assigned to a group of four participants and had to solve as many mazes as possible under several payment schemes. Subjects sat in individual booths and were not told where the other members of their group sat or how the others performed until the end of the experiment. It should be noted that students in the current study had relatively fewer siblings than the average number of siblings (1.46) reported in the Japanese Survey on Household Trends (JSHT) conducted by the Ministry of Health, Labour and Welfare. Thus, the present sample has relatively lower variation in sibling composition than a larger representative of teenagers in Japan.

\section{2-2. Experimental design and procedure}

Experimental design largely followed the framework used by Niederle and Versturlund (2007). The experiment consisted of a practice session and six tasks. In the practice session, subjects solved mazes on a computer screen for one minute to learn the solutions to the mazes. Figure 1 shows a screenshot of the subjects' display. Subjects 
moved cursors from the start to the goal point by using arrow keys on their keyboard. They could skip as many mazes as they wanted by clicking a skip button on their screen to move to the next maze. They received no payment for their performance in the practice session. After completing the practice session, subjects moved on to the actual tasks, where they were required to solve as many mazes as possible in three minutes under different payment schemes. In Task 1, subjects were paid on a piece rate: they received 25 points for every correctly solved maze. Task 2 employed a tournament payment scheme: the subject who correctly solved the largest number of mazes in each group received 100 points for every correctly solved maze, while the other three members received zero points. Since points earned under the tournament payment scheme depended on the performance of the other three members in the same group, subjects were exposed to a competitive environment under the tournament payment scheme. The two payment schemes were repeated in Tasks 3 and 4, as improvements in performance between the two payment schemes could reflect a learning effect rather than an actual response to competition. In Task 5, subjects were asked to choose whether they wanted to be paid under a piece-rate or tournament scheme before solving the mazes. The choice in Task 5 was then used to measure each subject's propensity to compete.

Importantly, just because a subject chooses to participate in the tournament scheme in Task 5, it does not immediately indicate that he or she prefers competition. The choice in Task 5 can also reflect factors not directly related to the preference for competition. For example, some might choose the tournament scheme because they overestimate their relative abilities in a group (overconfidence). Others might choose the piece-rate scheme because they are risk-averse (risk aversion) or dislike being 
informed about their performance relative to others (feedback aversion). It is also possible that some subjects choose the tournament because they know that their maze-solving abilities are sufficiently high (performance level).

The goal of implementing Task 6 was to reveal whether the participants' decision to compete in Task 5 could be explained solely by the reasons mentioned above or because subjects had a higher preference for competition. In Task 6, subjects were asked to choose whether they wanted to be compensated under the piece-rate or tournament scheme for their performance in Task 3, the second piece-rate task. If participants chose the piece-rate scheme, they received 25 points for every correctly solved maze in Task 3; if they chose the tournament scheme, they received 100 points for every correctly solved maze in Task 3 if they were the best performer and zero points if they were not. Because this payment was based on their past performance, subjects did not solve any mazes in Task 6 but speculated on their relative performance within the group. Thus, participants' choices in Task 6 were influenced by factors such as overconfidence, risk-aversion, feedback aversion, and performance level, but not by the preference for competition (Niederle and Vesterlund, 2007). Conversely, choices in Task 5 involved actual competition as well as speculation on their relative performance. Thus, the decision to enter competition in Task 5 could be seen as reflecting individual tastes for participating in competitions, in addition to overconfidence, risk aversion, and feedback aversion. By examining the differences in payment scheme choices between Tasks 5 and 6, individual preferences for competition would be revealed.

After completing Tasks 1-5, subjects were asked to guess their rank in their group by entering the subjective probability distribution of their rank. For example, a subject would type $100 \%$ for rank 1 and $0 \%$ for ranks 2 to 4 if he or she was very 
confident that he or she was the best performer in the group. The estimated expected ranks were then used to infer the extent of overconfidence for analysis. Unlike in Niederle and Vesterlund (2007), subjects were not paid for each correct guess of their rank. $^{11}$

To accurately evaluate participants’ attitudes toward competition, students were incentivized in the following way. At the end of the experiment, subjects drew a lottery and randomly selected one task among the six for which the reward was actually given. Students were paid according to the points earned in the selected task, plus 500 points for a participation fee. Subjects were given prizes for their points instead of cash because cash transactions were prohibited by the high schools. The prizes consisted of various stationery items, and subjects received different combinations of these items depending on their performance. ${ }^{12}$ Special care was taken not to mention the specific prizes that subjects would receive until the end of the experiment because the subjective value of the prizes could vary across subjects; subjects were simply told to earn as many points as possible.

At the end of the experiment, participants were asked to complete a questionnaire asking about demographic information, including sibling composition. The information was used to examine the extent to which sibling structure systematically affected a subject's choice for the tournament scheme in Tasks 5 and 6, thereby revealing their preference for competition.

\footnotetext{
11 This is due to the fact that some students chose a strategy of solving no mazes and picked rank 4 in our early version of the experiment.

12 Prizes were selected with permission from the high schools. Prizes included three colored clips (25 points), a clear folder (50 points), memo-pad (100 points), five colored pens (500 points), a mechanical pencil plus a plastic school bag (1000 points), and a fabric school bag (1500 points). At the end of experiment, students received a combination of these rewards. 100 points are roughly equivalent to 100 JPY, which is about 1 USD at the time of writing.
} 


\section{Results}

\section{3-1. Testing Sibling Hypothesis}

Figure 2 presents the proportion of participants who chose to compete in the tournament in Task 5 by gender and sibling composition. The graphs are consistent with the sibling hypothesis suggested by Brim (1958) and Sulloway (1996). Despite the fact that men generally entered the tournament more often than women did, the gender gap was remarkably reduced when certain groups of subjects were compared. For example, while $38 \%$ of men who have an older sister entered the tournament in Task 5, 39\% of women who have a younger brother also chose the tournament scheme. However, the variation in preference for competition by sibling composition is not immediately evident in Figure 2. As mentioned in section 2, the raw differences in tournament choice could indicate variation in the other confounding factors, such as overconfidence, risk aversion, feedback aversion, and performance level.

For this reason, we formally tested our hypothesis by estimating a probit model of payment scheme choice at Task 5, where the dependent variable equaled one if a subject chose the tournament payment scheme and zero otherwise. This model controls for performance level, as well as the tournament choice at Task 6 (e.g., overconfidence, risk aversion, feedback aversion). Since the choice at Task 6 did not involve the maze-solving task, but because subjects still had to speculate on how many mazes the other members in their group solved, controlling for the tournament choice at Task 6 removes the factors other than preference for competition. Performance in Tasks 3 and 4 was used to measure the actual performance level of subjects in order to alleviate any learning effects, as the number of correctly solved mazes increased in later tasks, as 
reported in Table 1.

Table 2 shows the estimated marginal effects from probit models of tournament choice in Task 5, where sibling composition dummies and their interactions with a female dummy are included in columns (a) and (b). The baseline for sibling composition dummies is "only sons." Columns (a) confirms that sibling composition significantly affected the decision to enter the tournament in Task 5 using a probit estimation. For instance, having older or younger sisters significantly reduced the probability of a male entering the tournament compared with men who are only sons. Similarly, the estimated coefficient for women who have younger brothers is significantly positive (0.314), although the total effect of having younger brothers compared with being an only daughter (0.314 and -0.327) only moderately differs from zero $(p$-value $=0.0973)$. In column $(b)$, these effects remained after controlling for performance level and choice of tournament entry in Task 6, except for the effect of men with younger sisters. Conditional upon performance level and the decision in Task 6, compared with only sons, having older sisters reduced men's propensity to select the tournament scheme by 35\%. This decrease is comparable to the negative effect of being female on tournament choice (-0.371). Having younger brothers increased the probability of women entering the tournament, although the total effect is only marginally significant $(\mathrm{p}$-value $=0.1108) .{ }^{13}$

As a reference, columns (c), (d), and (e) report estimation results similar to Niederle and Vesturlund (2007), testing whether women shy away from competition simply because they dislike it. According to column (a), women are 37.6\% less likely than men to select the tournament scheme. This significant gender effect remains even

${ }^{13}$ However, note that a coefficient of "Has any younger brothers" is not significantly estimated. 
after controlling for subjects' performance level, as well as other general factors such as the extent of overconfidence listed in columns (d) and (e). This suggests that women did not enter the tournament in Task 5 because of the other factors (e.g., overconfidence, risk aversion, feedback aversion, performance level) as was concluded in the Niederle and Vesturlund study (2007). The estimated negative effect of being female on tournament choice in column (e) is twice that found in Niederle and Vesterlund (2007).

The Appendix Table presents similar results as Table 2, but with the dependent variable replaced by tournament choice in Task 6, where no maze-solving activity was involved. No significant effects were found for either the female dummy or the sibling composition dummies in the Appendix Table, indicating that differences relating to sibling composition were due to personal preference for competition, not to performance level, and the other factors. This is consistent with our findings in Table 2, where the size of negative effect of being female remains similar across specifications. Thus, preference for competition plays a major role in explaining the differences by gender and sibling composition in tournament entry in Task 5.

Table 3 tests several hypotheses that attempt to explain why sibling composition, such as having an older sister, may affect preference for competitive environments. Specifically, we directly test the original sibling hypothesis proposed by Brim (1958) and Sulloway (1996) by adding birth order terms as well as cross-gender sibling dummies. As in Table 2, the dependent variable was assigned a value of one if a subject selected the tournament payment scheme in Task 5 and zero if they did not. All analyses controlled for the same set of explanatory variables as in column (e) of Table 2, but some estimates are not presented in the table to save the space.

In column (a), birth order and its interaction term with a female dummy are 
included. Columns (b) and (c) include first-born, middle-born, and last-born dummies to account for the possibility that the effect of birth order is non-linear. The basis for these dummies is a dummy of an only child in the family in column (c). Both columns (a) and (b) report no significant estimates for birth order and first-born dummy, but there was a significant positive estimate for an interaction between middle-born and female dummies in column (c). The null hypothesis that the total effect of being a middle-born female child (0.502 and -0.231) is zero can moderately be rejected ( $\mathrm{p}$-value $=0.081$ ) This result is consistent with the birth order hypothesis proposed by Sulloway (1996), where middle-born children are reported to fare less well than their older and younger siblings, and thus are more likely to be rebellious.

Columns (d) and (e) examine the possibility that the total number of cross-gender siblings, rather than the relative order among siblings, is important in shaping preferences for competition. Along these lines, Brunello (2013) found that only having sisters at the age of 15 significantly increased the probability of engaging in leadership activities in middle and high school for both girls and boys in the U.S., and that it increased the probability of participating in sports clubs for Japanese boys. Although no such effect is detected in our analysis in column (e), the number of female siblings does decrease the probability of men entering the tournament scheme in column (d). Surprisingly, the magnitude of having one sister is comparable to the negative entry effect observed among women: having one sister reduces the probability of men entering the tournament by $35.3 \%$.

\section{3-2. How much did they gain or lose?}

While some women are averse to entering competitive environments, resulting 
in them being underrepresented on the corporate ladder, women with younger brothers may gain by making "right" decisions to enter the competition when they are likely to win. To assess the magnitude of sibling structure on subjects' welfare, Figure 3 shows how much subjects gained or lost by selecting or avoiding a competitive environment. Specifically, it indicates the average cost of over or under entry into the tournament in Task 5, measured by experiment-point. The costs were calculated by estimating the expected losses or gains from entering the tournament, and then taking the difference from the actual points earned in Task 5. ${ }^{14}$ Tables under the graph show the proportion of those who entered the tournament when they should not have (i.e., their expected gain for not entering the tournament is higher), along with the proportion of those who did not enter the tournament when they should (i.e., their expected gain from entering the tournament is higher). Overall, the cost of under-entry is larger for women than for men, but the cost of over-entry is smaller for women. However, these costs vary significantly across sibling composition: among women, those who have younger brothers suffered the least from under-entry as they entered the tournament more often. On the other hand, men who have older sisters incurred the least over-entry cost by not entering the tournament as much. Interestingly, women who have younger brothers suffered from the largest over-entry cost among women; older sisters with younger brothers decided to compete too often, even when they should not have based on their performance.

\footnotetext{
${ }^{14}$ The expected gains and losses from entering the tournament were calculated by randomly assigning each subject into a group of four students 100,000 times in order to estimate their probability of winning the tournament in Task 5. For instance, for those who correctly solved 12 mazes, the probability of winning the tournament was $18.2 \%$, so the expected gain from entering the tournament (218.4 points) would be lower than the expected gain from choosing the piece-rate (300 points). For those who correctly solved 13 mazes, the probability of winning the tournament was $36.8 \%$; thus, these participants should have entered the tournament because the expected gain, 477.8 points, was higher than the piece-rate reward (325 points). It was assumed that the cost of solving mazes is zero for all subjects and that their performance was independent of the payment scheme.
} 


\section{Discussion}

This study explored a previously uninvestigated environmental factor that could have a considerable influence on an individual's decision to compete. We conducted a simple laboratory experiment similar to the one designed by Niederle and Vesterlund (2007) on Japanese high school students. Our experiment showed that women were significantly less likely to choose to compete than men were, which is consistent with the findings of Niederle and Vesterlund (2007). More importantly, we also found that the decision to compete varied significantly according to sibling structure, thereby supporting the long-debated sibling hypothesis in psychology from the viewpoint of experimental economics.

One interesting finding reported here that is consistent with previous studies is that middle-born females showed a higher propensity to choose the tournament option in Task 5. According to Sulloway (1996), middle-born children are "losers in ... Darwinian calculus," not only because the higher reproductive value of the first-born child encourages parents to invest more in first-borns, but also because a last-born child is "the only member of the family to receive parental investment undiluted by the needs of a younger rival.” Indeed, according to Salmon and Daly (1998), middle-born children are significantly less likely to nominate their mothers as the person they feel closest to than first- or last-born children, implying that middle-born children receive less parental investment. Surrounded by both older and younger rivals, the disadvantaged middle-born child is required to be even more aggressive in the competition for parental resources. The results in column (c) of Table 3 hint at this propensity to compete in middle-born women.

Another interesting finding is that men with older sisters were no more likely to 
compete than women were, while women with younger brothers were more likely to compete when compared with women who are only daughters, although this result is only moderately significant (column (b), Table 2). This finding is in line with Sulloway's (1996) theory, where he suggests a combined effect of birth order and cross-gender sibling dynamics on older sister / younger brother pairs. While Sulloway’s (1996) explanation is derived from evolutionary science, where older siblings have advantages when competing for parental investments, other psychological mechanisms are also thought to play a role. Stewart (1983) observed the behaviors of preschool children when they were left alone with their infant siblings, and found that older siblings were most active when caring for their younger cross-gender siblings. Older sisters in particular tended to give far more care to their younger brothers than was sought (Stewart, 1983). This study, along with that of Brim (1958), indicate that younger brothers with "meddlesome" older sisters may not have to compete as much for the limited resources of parents, which may have provided them with fewer opportunities to nurture their competitive attitudes. Thus, the systematic trend observed in the preference for competition among older sister and younger brother pairs may arise not only from sibling competition, as originally suggested by evolutionary science, but also from an interaction specific to this pair, as raised in some psychological studies.

Finally, and most importantly, our study lends support for institutional reforms that promote interactions between women and younger men. Exposing women to experiences where they are in a position to overrule younger men may help cultivate their willingness to compete with men. This tactic may be especially effective in patriarchal societies and should be started at an early age, as observed by Stewart (1983). 


\section{References}

Adler, A. (1928). Characteristics of the first, second, and third child. Children, 3, 14-52.

Archer, J. (2006). Testosterone and human aggression: An evaluation of the challenge hypothesis. Neuroscience and Biobehavioral Reviews, 30, 319-345.

Beer, J.M. and Horn, J.M. (2000). The influence of rearing order on personality development within two adoption cohorts. Journal of Personality, 68, 789-819.

Booth, A.L., Cardona, L., and Nolen, P.J. (2011). Gender differences in risk aversion: Do single-sex environments affect their development? IZA Discussion Paper No. 6133.

Booth, A.L. and Nolen, P.J. (2012a). Choosing to compete: How different are girls and boys? Journal of Economic Behavior and Organization, 81, 542-555.

Booth, A.L. and Nolen, P.J. (2012b). Gender Differences in Risk Behaviour: Does Nurture Matter? Economic Journal, 122, F56-F78.

Booth, A.L., Cardona-Sosa L., and Nolen, P. (2014). Gender differences in risk aversion: Do single-sex environment affect their development? Journal of Economic Behavior and Organization, 99, 126-154.

Brim, O.G. Jr. (1958). Family structure and sex role learning by children: A further analysis of Helen Koch's data. Sociometry, 21, 1-16.

Buser, T. (2012). The impact of the menstrual cycle and hormonal contraceptives on competitiveness. Journal of Economic Behavior and Organization, 83, 1-10.

Carrell, S.E., Page, M.E., and West, J.E. (2010). Sex and science: How professor gender perpetuates the gender gap. The Quarterly Journal of Economics, 125, 1101-1144.

Coates, J.M., Gurnell, M., and Rustichini, A. (2009). Second-to-fourth digit ratio predicts success among high-frequency financial traders. Proceedings of the National Academy of Sciences, 106, 623-628.

Dreber, A., and Hoffman, M. (2007). Portfolio selection in utero. Paper presented at 19th Annual Human Behavior and Evolution Society Conference, University of Chicago.

Ernst, C. and Angst, J. (1983). Birth order: Its influence on personality, Berlin, Germany: Springer-Verlag.

Gneezy, U., Leonard, K.L., and List, J.A. (2009). Gender differences in competition: Evidence from a matrilineal and a patriarchal society. Econometrica, 77, 1637-1664.

Guéguen, N. (2012). Risk taking and women's menstrual cycle: Near ovulation, women avoid a doubtful man. Letters on Evolutionary Behavioral Science, 3, 1-3.

Healey, M.D. and Ellis, B.J. (2007). Birth order, conscientiousness, and openness to experience: Tests of the family-niche model of personality using a within-family methodology. Evolution and Human Behavior, 28, 55-59.

Hoffman, M. and Gneezy, U. (2010). Left-handed women are more competitive than right-handed men: On the biological basis of gender differences in competitiveness. Working Paper, University of California, San Diego. 
Jefferson, T., Herbst, J.H., and MacCrae, R.R. (1998). Associations between birth order and personality traits: Evidence from self-reports and observer ratings. Journal of Research in Personality, 32, 498-509.

Koch, H. L. (1954). The relation of "primary mental abilities” in five- and six-year olds to sex of child and characteristics of his siblings. Child Development 25:209-23.

Marini, V. and Kurtz, J.E. (2011). Birth order differences in normal personality traits: Perspectives from within and outside the family. Personality and Individual Differences, 51, 910-914.

Niederle, M. and Vesturland, L. (2007). Do women shy away from competition? Do men compete too much? The Quarterly Journal of Economics, 122, 1067-1101.

Niederle, M. and Vesturland, L. (2011). Gender and competition. Annual Review of Economics, 3, 601-30

Niederle, M., Segal, C., and Vesterlund, L. (in press). How costly is diversity? Affirmative action in light of gender differences in competitiveness. Management Science.

Paulhus, D.L., Trapnell, P.D., and Chen, D. (1999). Birth order effects on personality and achievement within families. Psychological Science, 10, 482-488.

Saroglou, V. and Fiasse, L. (2003). Birth order, personality, and religion: A study among young adults from a three-sibling family. Personality and Individual Differences, 35, 19-29.

Salmon, C.A. and Daly, M. (1998). Birth order and familial sentiment: Middleborns are different. Evolution and Human Behavior, 19, 299-312.

Stewart, R.B. (1983). Sibling attachment relationships: Child-infant interaction in the strange situation. Development Psychology, 19, 192-199.

Sulloway, F.J. (1996). Born to rebel: Birth order, family dynamics, and creative lives. New York, NY: Pantheon Books.

Tamiya, R., Lee, S.Y., and Ohtake, F. (2012). Second to fourth digit ratio and the sporting success of sumo wrestlers. Evolution and Human Behavior, 33, 130-136.

Wozniak, D., Harbaugh, W.T., and Mayr, U., (2014). The menstrual cycle and performance feedback alter gender differences in competitive choice. Journal of Labor Economics, 32:1, 161-198. 


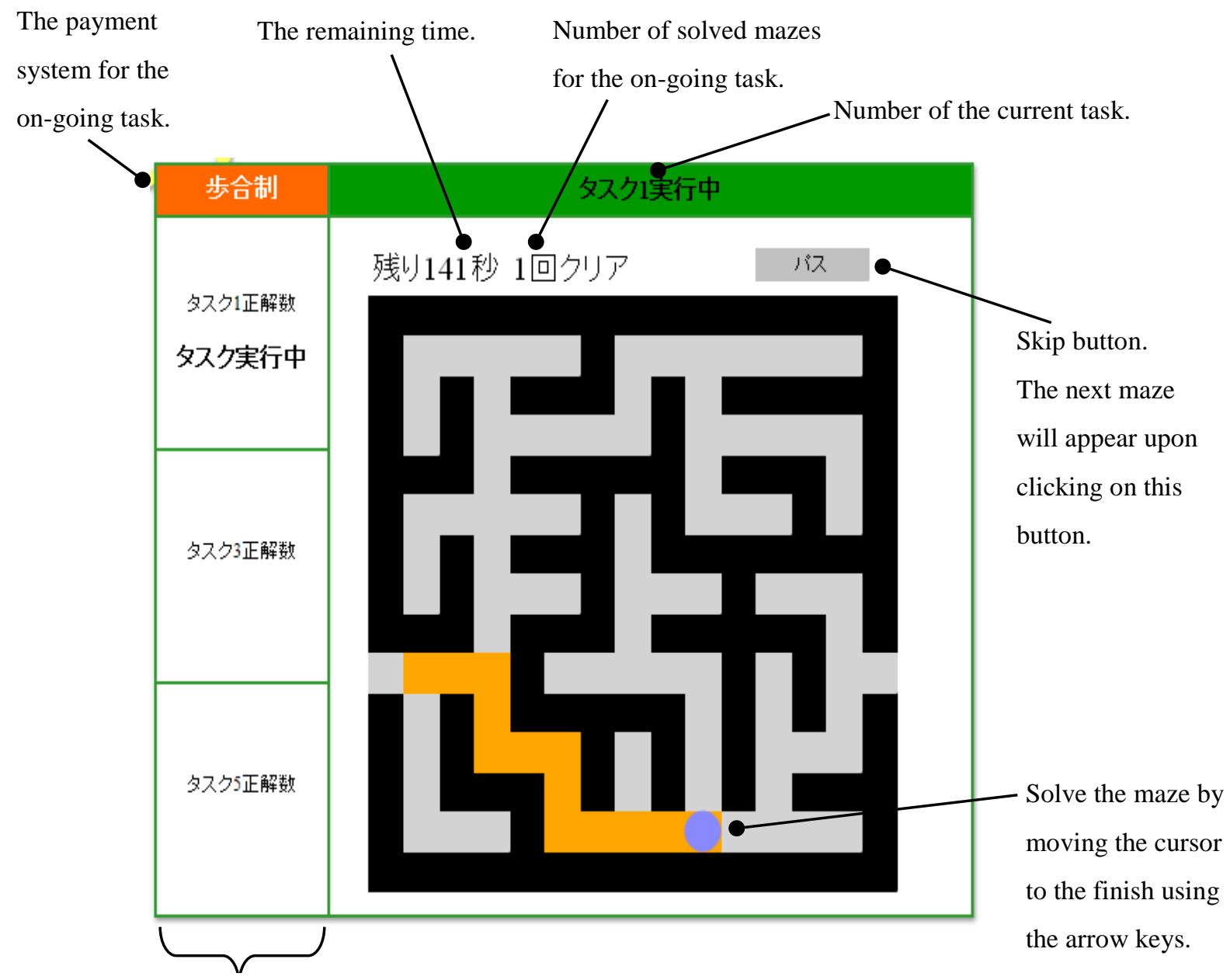

Numbers of correctly solved mazes for the completed tasks.

\section{Figure 1. Overview of Basic Screen}


Table 1. Summary statistics (mean)

\begin{tabular}{lcc}
\hline & Male & Female \\
\cline { 2 - 3 } Age & 16.90 & 16.82 \\
Number of siblings & 1.10 & 0.96 \\
Number of female siblings & 0.68 & 0.60 \\
Birth order & 1.51 & 1.52 \\
& & \\
Tournament Choice in Task 5 (=1) & 0.61 & 0.23 \\
Tournament Choice in Task 6 (=1) & 0.37 & 0.27 \\
& & \\
Task 1 performance (piece-rate) & 11.02 & 9.88 \\
Task 2 performance (tournament) & 12.00 & 10.74 \\
Task 3 performance (piece-rate) & 12.51 & 11.44 \\
Task 4 performance (tournament) & 12.24 & 11.63 \\
Task 5 performance (choice) & 12.95 & 11.71 \\
Guessed rank in Task 3 & 2.17 & 2.51 \\
Guessed rank in Task 4 & 2.15 & 2.54 \\
& & \\
Average points earned per Task & 437.70 & 343.44 \\
Cost of over-entry (Task 5) & 67.07 & 36.17 \\
Cost of under-entry (Task 5) & 203.05 & 288.83 \\
& & \\
Number of Observations & 41 & 94 \\
\hline
\end{tabular}


(A) Male

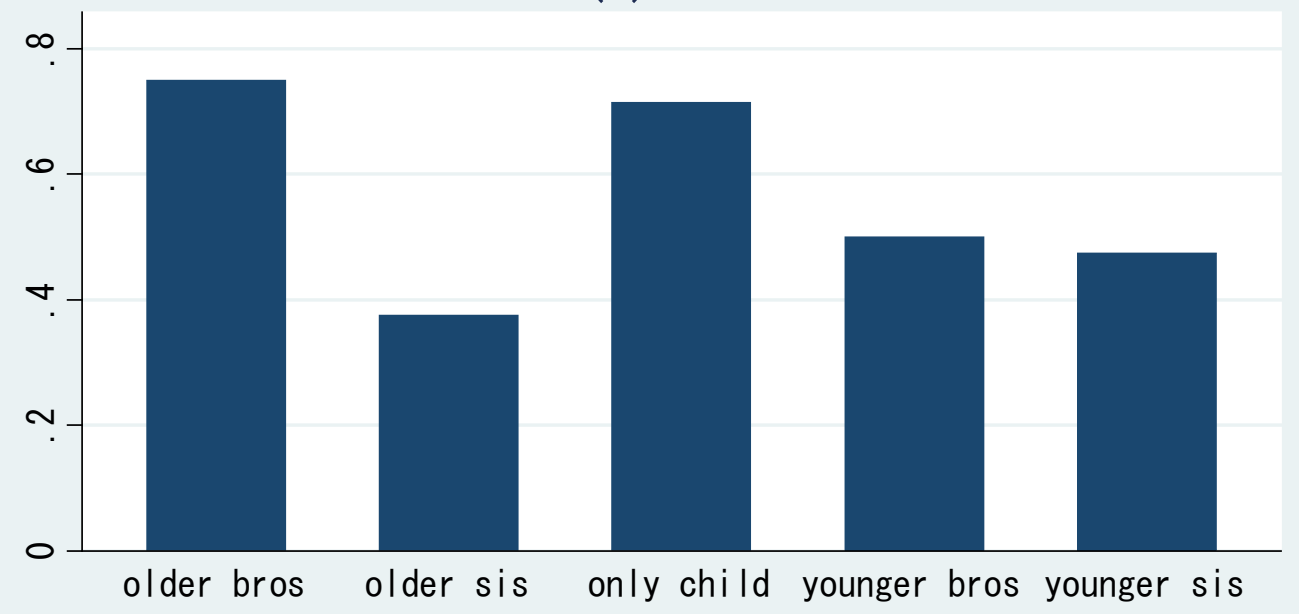

(B) Female

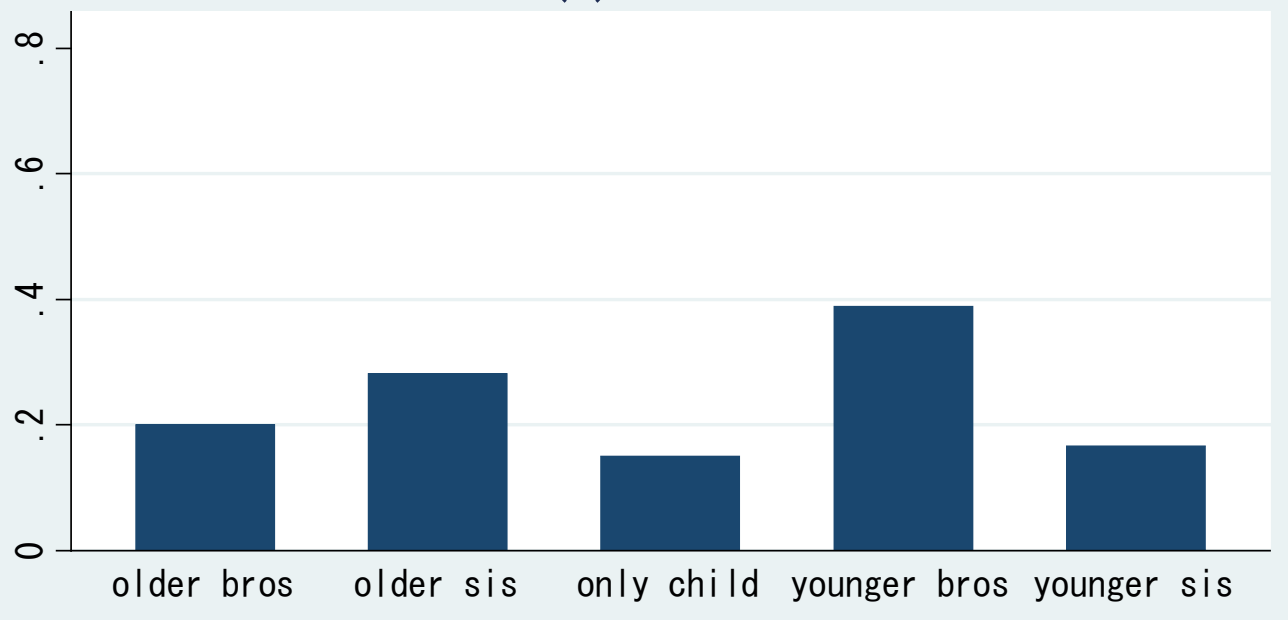

Figure 2. Proportion of participants who chose to compete in Task 5 by sibling composition

Note. The leftmost bar indicates the proportion of tournament entries for subjects who have an older brother, for instance. 
Table 2. Probit of decision to compete in Task 5

\begin{tabular}{|c|c|c|c|c|c|}
\hline & \multicolumn{5}{|c|}{ Marginal effect (standard error) } \\
\hline & (a) & (b) & (c) & (d) & (e) \\
\hline \multirow[t]{2}{*}{ Female } & $-0.569^{* * *}$ & $-0.371^{* *}$ & $-0.376^{* * *}$ & $-0.310^{* * *}$ & $-0.323^{* * *}$ \\
\hline & $(0.110)$ & $(0.148)$ & $(0.088)$ & $(0.098)$ & $(0.092)$ \\
\hline \multirow[t]{2}{*}{ Submitting the tournament in Task 6} & & $0.272^{* *}$ & & & $0.220 * *$ \\
\hline & & $(0.127)$ & & & $(0.106)$ \\
\hline \multirow[t]{2}{*}{ Performance in Task 4} & & 0.003 & & 0.012 & 0.010 \\
\hline & & $(0.032)$ & & $(0.024)$ & $(0.030)$ \\
\hline \multirow[t]{2}{*}{ Differences in performances (Task3 - Task4) } & & -0.057 & & $-0.0678 * * *$ & $-0.0552 *$ \\
\hline & & $(0.040)$ & & $(0.026)$ & $(0.033)$ \\
\hline \multirow[t]{2}{*}{ Guessed rank in Task 4} & & $-0.163 * *$ & & $-0.172 * * *$ & $-0.177 * *$ \\
\hline & & $(0.081)$ & & $(0.066)$ & $(0.075)$ \\
\hline \multirow[t]{2}{*}{ Has any younger brothers } & -0.327 & -0.283 & & & \\
\hline & $(0.262)$ & $(0.192)$ & & & \\
\hline \multirow[t]{2}{*}{ Has any younger brothers * female } & $0.314^{* *}$ & $0.490 * * *$ & & & \\
\hline & $(0.128)$ & $(0.184)$ & & & \\
\hline \multirow[t]{2}{*}{ Has any older brothers } & 0.060 & 0.170 & & & \\
\hline & $(0.217)$ & $(0.190)$ & & & \\
\hline \multirow[t]{2}{*}{ Has any older brothers * female } & -0.032 & -0.131 & & & \\
\hline & $(0.261)$ & $(0.316)$ & & & \\
\hline \multirow[t]{2}{*}{ Has any younger sisters } & $-0.250 * *$ & -0.228 & & & \\
\hline & $(0.108)$ & $(0.203)$ & & & \\
\hline \multirow[t]{2}{*}{ Has any younger sisters * female } & 0.334 & 0.178 & & & \\
\hline & $(0.244)$ & $(0.230)$ & & & \\
\hline \multirow[t]{2}{*}{ Has any older sisters } & $-0.245^{* *}$ & $-0.350 * *$ & & & \\
\hline & $(0.116)$ & $(0.193)$ & & & \\
\hline \multirow[t]{2}{*}{ Has any older sisters * female } & $0.440 * *$ & $0.348^{* *}$ & & & \\
\hline & $(0.182)$ & $(0.156)$ & & & \\
\hline Number of Observations & 135 & 135 & 135 & 135 & 135 \\
\hline Log Likelihood & -73.14 & -64.4 & -78.57 & -71.59 & -69.19 \\
\hline Psuedo R-squared & 0.162 & 0.262 & 0.0995 & 0.179 & 0.207 \\
\hline
\end{tabular}


Table 3. The impact of sibling structure on the decision to compete in Task 5

\begin{tabular}{|c|c|c|c|c|c|}
\hline & \multicolumn{5}{|c|}{ Marginal effect (standard error) } \\
\hline & (a) & (b) & (c) & (d) & (e) \\
\hline Female & $\begin{array}{r}-0.417^{* *} \\
(0.187)\end{array}$ & $\begin{array}{r}-0.349 * * * \\
(0.102)\end{array}$ & $\begin{array}{r}-0.493^{* * *} \\
(0.125)\end{array}$ & $\begin{array}{r}-0.391^{* * *} \\
(0.123)\end{array}$ & $\begin{array}{r}-0.277^{* *} \\
(0.117)\end{array}$ \\
\hline Birth order & $\begin{array}{r}-0.00218 \\
(0.136)\end{array}$ & & & & \\
\hline Birth order * female & $\begin{array}{r}0.0545 \\
(0.168)\end{array}$ & & & & \\
\hline First born & & $\begin{array}{r}-0.106 \\
(0.180)\end{array}$ & $\begin{array}{r}-0.177 \\
(0.252)\end{array}$ & & \\
\hline First born * female & & $\begin{array}{r}0.082 \\
(0.210)\end{array}$ & $\begin{array}{r}0.27 \\
(0.197)\end{array}$ & & \\
\hline Middle born & & & $\begin{array}{r}-0.231 \\
(0.181)\end{array}$ & & \\
\hline Middle born * female & & & $\begin{array}{r}0.502^{* * *} \\
(0.157)\end{array}$ & & \\
\hline Last born & & & $\begin{array}{r}0.102 \\
(0.308)\end{array}$ & & \\
\hline Last born * female & & & $\begin{array}{r}0.156 \\
(0.362)\end{array}$ & & \\
\hline Number of female siblings & & & & $\begin{array}{r}-0.353^{* *} \\
(0.181)\end{array}$ & \\
\hline Number of female siblings $*$ female & & & & $\begin{array}{c}0.374 * \\
(0.216)\end{array}$ & \\
\hline Number of male siblings & & & & $\begin{array}{r}-0.0302 \\
(0.163)\end{array}$ & \\
\hline Number of male siblings $*$ female & & & & $\begin{array}{r}0.243 \\
(0.204)\end{array}$ & \\
\hline Having same-sex siblings only & & & & & $\begin{array}{r}0.228 \\
(0.204)\end{array}$ \\
\hline Having same-sex siblings only * female & & & & & $\begin{array}{l}-0.219 \\
(0.197)\end{array}$ \\
\hline Number of Observations & 135 & 135 & 135 & 135 & 135 \\
\hline Log Likelihood & -72.13 & -69.00 & -66.71 & -65.16 & -68.61 \\
\hline Psuedo R-squared & 0.173 & 0.209 & 0.235 & 0.253 & 0.214 \\
\hline
\end{tabular}

Note. This table reprents the marginal effects from probit model estimation. The dependent variable is given a value of 1 if the subject selected the tournament payment scheme in Task 5 , else it is assigned a 0 . All estimations control for a dummy to indicate the choice of tournament in Task 6, the number of correctly solved mazes in Task 4, the difference in performance in Tasks 3 and 4, and the guessed rank in Task 4. Marginal effects are evaluated for a female with an average number of correct answers in Tasks 3 and 4, who chooses the tournament option, believes she is ranked second on Task 4, and for columns (a), (b), and (c) is the first-born child, for column (d) has one brother, and for column (e) has siblings of both gender.. ${ }^{* * *} \mathrm{p}<0.01$, ** $\mathrm{p}<0.075,{ }^{*} \mathrm{p}<0.1$. 


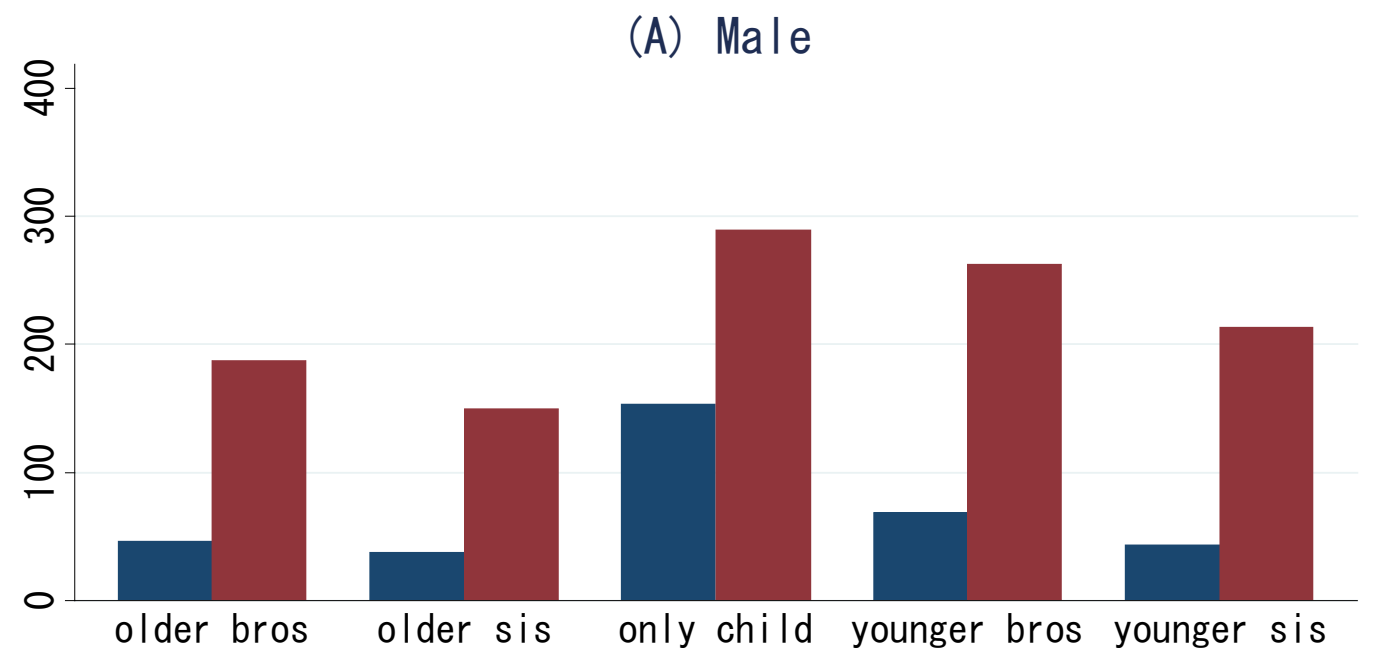

\begin{tabular}{lccccc}
\hline & older bros & older sis & only child & younger bros & younger sis \\
\hline Should not enter & $16.7 \%$ & $12.5 \%$ & $57.1 \%$ & $25.0 \%$ & $15.8 \%$ \\
Should enter & $16.7 \%$ & $12.5 \%$ & $28.6 \%$ & $25.0 \%$ & $21.1 \%$ \\
\hline
\end{tabular}

(B) Female

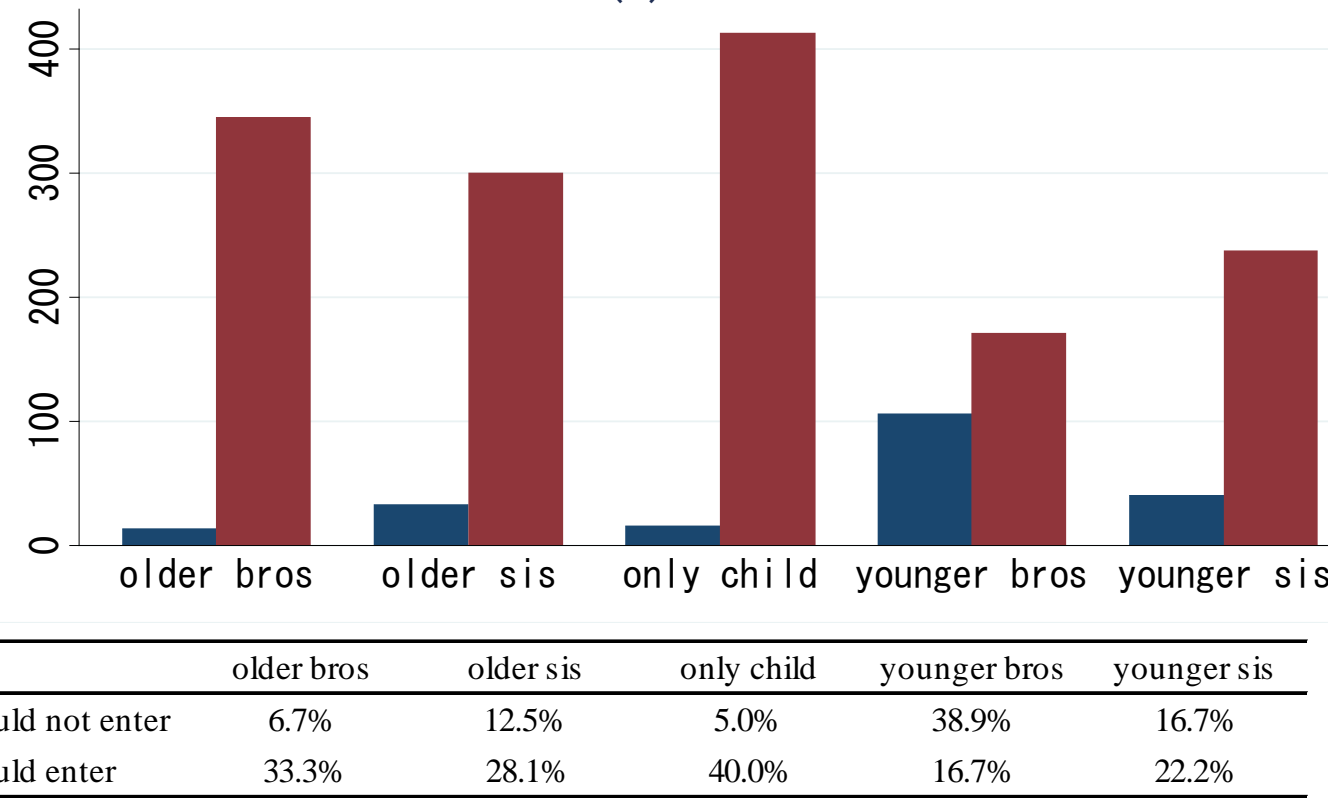

Figure 3. Average cost of over-entry (Blue) and under-entry (Red) in Task 5

Note. Bars indicate the average costs of under/over-entry into the tournament in Task 5 . The vertical axis measures the costs in experiment points. Tables under the graph show the proportion of those who entered the tournament when they should not have (i.e., their expected gain for not entering the tournament is higher), and the proportion of those who did not enter the tournament when they should have (i.e., their expected gain for entering the tournament is higher). 
Appendix Table. Probit of decision to compete in Task 6 (no maze-solving activity)

\begin{tabular}{|c|c|c|c|c|c|}
\hline & \multicolumn{5}{|c|}{ Marginal effect (standard error) } \\
\hline & (a) & (b) & (c) & (d) & (e) \\
\hline \multirow[t]{2}{*}{ Female } & -0.159 & 0.0397 & -0.0999 & -0.0364 & -0.0162 \\
\hline & $(0.188)$ & $(0.100)$ & $(0.088)$ & $(0.084)$ & $(0.095)$ \\
\hline \multirow[t]{2}{*}{ Performance in Task 3} & & 0.013 & & $0.0404 *$ & 0.024 \\
\hline & & $(0.018)$ & & $(0.021)$ & $(0.025)$ \\
\hline \multirow[t]{2}{*}{ Differences in performances (Task3 - Task4) } & & $-0.0385 * *$ & & $-0.0461^{* *}$ & $-0.0499 * *$ \\
\hline & & $(0.020)$ & & $(0.020)$ & $(0.023)$ \\
\hline \multirow[t]{2}{*}{ Guessed rank in Task 3} & & $-0.139 * *$ & & & $-0.178 * *$ \\
\hline & & $(0.077)$ & & & $(0.069)$ \\
\hline \multirow[t]{2}{*}{ Has any young brothers } & -0.248 & -0.358 & & & \\
\hline & $(0.314)$ & $(0.354)$ & & & \\
\hline \multirow[t]{2}{*}{ Has any young brothers $*$ female } & 0.105 & 0.066 & & & \\
\hline & $(0.188)$ & $(0.148)$ & & & \\
\hline \multirow[t]{2}{*}{ Has any older brothers } & -0.004 & 0.157 & & & \\
\hline & $(0.146)$ & $(0.209)$ & & & \\
\hline \multirow[t]{2}{*}{ Has any older brothers *female } & -0.026 & -0.107 & & & \\
\hline & $(0.183)$ & $(0.084)$ & & & \\
\hline \multirow[t]{2}{*}{ Has any younger sisters } & -0.142 & -0.027 & & & \\
\hline & $(0.088)$ & $(0.102)$ & & & \\
\hline \multirow[t]{2}{*}{ Has any younger sisters * female } & 0.254 & 0.117 & & & \\
\hline & $(0.249)$ & $(0.227)$ & & & \\
\hline \multirow[t]{2}{*}{ Has any older sisters } & -0.006 & 0.022 & & & \\
\hline & $(0.157)$ & $(0.152)$ & & & \\
\hline \multirow[t]{2}{*}{ Has any older sisters * female } & -0.100 & -0.078 & & & \\
\hline & $(0.137)$ & $(0.104)$ & & & \\
\hline Number of Observations & 135 & 135 & 135 & 135 & 135 \\
\hline Log Likelihood & -79.07 & -64.05 & -81.37 & -72.38 & -67.58 \\
\hline Psuedo R-squared & 0.0362 & 0.219 & 0.00815 & 0.118 & 0.176 \\
\hline
\end{tabular}

Note.This table reprents the marginal effects from probit model estimation. The dependent variable is given a value of 1 if the subject selected the tournament payment scheme in Task 6, else it is assigned a 0. Marginal effects are evaluated for a female with an average number of correct answers in Tasks 3 and 4 , who chooses the tournament option, believes she is ranked second on Task 3 , and has a younger brother.*** $\mathrm{p}<0.01, * * \mathrm{p}<0.075, * \mathrm{p}<0.1$. 